calibrated even when this was corrected. The CAD consortium model (ESC 2013 guidelines), slightly under-estimated average CAD risk, but performed well once this was accounted for lower margin presents histogram of number of patients with each predicted risk score

\section{HEAD-TO-HEAD COMPARISON SHOWS POOR PERFORMANCE OF BOTH DIAMOND-FORRESTER AND PRYOR MODELS IN PREDICTING CORONARY ARTERY DISEASE IN CHEST PAIN PATIENTS: A SINGLE CENTRE EXPERIENCE IN A LARGE COHORT OF PATIENTS}

Sharmaine Thiru*, Alexandros Alexopoulos, Adrian Chenzbraun. Royal Liverpool University Hospital

\subsection{6/heartjnl-2017-311726.89}

Background An optimal investigation strategy for patients with suspected angina pectoris (AP) remains elusive. UK and ESC guidelines use historical prediction models to guide management after the likelihood of coronary artery disease (CAD) is estimated by symptoms, demographics and risk factors profile (NICE UK guidelines - Pryor model) or by demographics and symptoms only (ESC guidelines - Diamond Forrester model). Data are accumulating suggesting that these prediction models grossly overestimate CAD prevalence in today patients. This is a prospective study to assess the actual CAD prevalence in patients referred to a chest pain clinic, as defined by either obstructive CAD or a positive functional test and the comparative performance of the two models in predicting CAD in these patients.

Methods 1376 consecutive patients (age: 58 12 years) were reviewed in a dedicated chest pain clinic. Patients were assigned to five estimated CAD likelihood groups: $<10 \%$, $10 \%-29 \%, 30 \%-60 \%, 61 \%-90 \%$ and $>90 \%$ using the NICE model and to three CAD likelihood groups: $<15 \%, 15 \%-$ $85 \%$ and $>85 \%$ using the ESC model. Patients were diagnosed as having CAD when either obstructive $(>70 \%)$ coronary stenoses were demonstrated by invasive angiogram or CTCA or a functional test was positive. The observed CAD prevalence was compared with the predicted one by the two models. Investigation strategies concordance between the NICE and ESC pathways was checked with kappa statistics and comparative diagnostic performance was assessed with ROCs.

Results 652 pts. (47\%) had non-anginal CP, 412 pts. (30\%) had atypical AP and 312 (23\%) had typical AP. 417 pts $(30 \%)$ were not investigated for CAD due to non-anginal symptoms and/or low CAD probability. Investigations were completed in $858 / 959$ pts. The actual CAD prevalence was $21 \%$ vs. a NICE (Pryor) model predicted one of $53 \%$ and an ESC (Diamond-Forrester) model predicted one of $36 \%$ $(\mathrm{p}<0.001)$. There was poor agreement $(k a p p a=0.07)$ between the two pathways as to investigations strategies, with the NICE pathway directing a much higher proportion of patients to invasive angiography when compared with the ESC one: 498/1386 (36\%) vs. 51/1386 (4\%), p <0.0001, respectively. Both models had modest predictive abilities with AUCs of 0.695 and 0.693 , respectively $(p=n s)-$ Figure 1 : Comparison of ROCs for CAD likelihood scores by the NICE and the ESC models.
Conclusions 1. The overall prevalence of CAD in patients referred for suspected AP is significantly lower than expected by using either NICE or ESC endorsed historical model.

2. The use of risk factors profile in addition to demographics and symptoms characteristics does not improve diagnostic accuracy and increases the degree of overestimation.

3. The present NICE pathway directs a much higher proportion of patients to invasive angiography than the ESC one

4. The present results emphasise the need to develop updated prediction models.

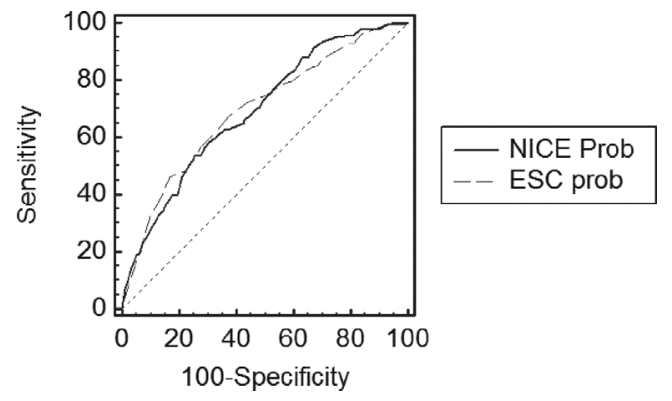

Abstract 90 Figure 1

\section{HOW USEFUL ARE RECENT STUDIES USING THE DIAMOND-FORRESTER RISK MODEL TO ASSESS CHEST PAIN?}

Kenneth Chan*, Rizwan Sarwar. Oxford Heart Centre

10.1136/heartjnl-2017-311726.90

Background The conventional method to assess stable chest pain of recent onset is to classify the nature of the chest pain, and then apply a risk model to predict the probability that it is caused by obstructive coronary artery disease (CAD), as recommended in American, European and NICE guidelines. The European and NICE guidelines are derived from the 1979 Diamond-Forrester risk model (DFRM), although this has been criticised for overestimating the risk of CAD. We hypothesised that recent studies would be more consistent and useful than earlier studies in diagnosing CAD.

Methods We performed a systematic literature search on studies published on MEDLINE and EMBASE until Nov 2016. Searched terms were Diamond Forrester and coronary artery disease. Overlapping studies and review articles were excluded. Data on the nature of chest pain and presence of CAD was independently extracted by both authors. Crude relative risks (CRR) of CAD were calculated by comparing typical angina and atypical angina respectively to non-anginal chest pain or pain free as the reference, and not taking into account demographics or cardiovascular risk factors.

Results 10 studies $(n=31,528)$ were eligible for analysis (mean age $59 \pm 10,54 \%$ male), as shown in Table 1 ; these used a variety of different methods to diagnose CAD. Table 2 shows that compared to the original DFRM, more recent studies tended to use cohorts that had larger of patients with atypical angina and non-anginal chest pain with positive diagnoses of CAD varying dramatically; such as of those with typical angina the\%age with CAD ranged from 9\%-88\%. There was 


\begin{tabular}{|c|c|c|c|c|c|}
\hline Reference & Publication & $n$ & $\begin{array}{l}\text { Age } \\
\text { (SD) }\end{array}$ & $\begin{array}{l}\text { \%age } \\
\text { male }\end{array}$ & Diagnosis of CAD \\
\hline $\begin{array}{l}\text { Diamond- } \\
\text { Forrester }\end{array}$ & NEJM 1979 & 4952 & - & - & - \\
\hline Jensen & JCCT 2009 & 551 & $\begin{array}{l}56 \\
(10)\end{array}$ & $46 \%$ & $70 \%$ stenosis CT \\
\hline PREDICT & $\begin{array}{l}\text { Ann Intern } \\
\text { Med } 2010\end{array}$ & 1166 & $\begin{array}{l}60 \\
(11)\end{array}$ & $58 \%$ & QCA angio $50 \%$ \\
\hline $\begin{array}{l}\text { CAD } \\
\text { Consortium }\end{array}$ & EHJ 2011 & 2272 & $\begin{array}{l}62 \\
(10)\end{array}$ & $67 \%$ & $50 \%$ stenosis CT \\
\hline $\begin{array}{l}\text { CONFIRM } \\
\text { male }\end{array}$ & Circ 2011 & 7719 & $\begin{array}{l}57 \\
(11)\end{array}$ & $100 \%$ & $50 \%$ stenosis CT \\
\hline $\begin{array}{l}\text { CONFIRM } \\
\text { female }\end{array}$ & & 6329 & $\begin{array}{l}60 \\
(11)\end{array}$ & - & - \\
\hline Pickett & $\begin{array}{l}\text { Am J Cardiol } \\
2013\end{array}$ & 1027 & $\begin{array}{l}50 \\
(12)\end{array}$ & $59 \%$ & $\begin{array}{l}50 \% \text { stenosis } \mathrm{CT} \text { of vessel } \\
1.5 \mathrm{~mm}\end{array}$ \\
\hline Chen & $\begin{array}{l}\text { PLOS One } \\
2014\end{array}$ & 377 & $64(9)$ & $69 \%$ & Gensini score 20 \\
\hline Winther & $\begin{array}{l}\text { Int J Cardiov } \\
\text { Im } 2016\end{array}$ & 228 & $\begin{array}{l}62 \\
(10)\end{array}$ & $53 \%$ & QCA angio $50 \%$ \\
\hline $\begin{array}{l}\text { PROMISE } \\
\text { male }\end{array}$ & $\begin{array}{l}\text { Circ Cardiov } \\
\text { Im } 2016\end{array}$ & 4246 & $59(8)$ & $100 \%$ & $\begin{array}{l}\text { Positive stress nuclear, stress } \\
\text { echo or exercise ECG }\end{array}$ \\
\hline $\begin{array}{l}\text { PROMISE } \\
\text { female }\end{array}$ & & 4270 & $62(8)$ & - & - \\
\hline PARTNERS & Circ 2016 & 2274 & $\begin{array}{l}56 \\
(13)\end{array}$ & $57 \%$ & $50 \%$ CT \\
\hline Ferreira & $\begin{array}{l}\text { Int J Cardiol } \\
2016\end{array}$ & 1069 & $\begin{array}{l}59 \\
(11)\end{array}$ & $41 \%$ & $50 \%$ CT \\
\hline \multicolumn{2}{|c|}{$\begin{array}{l}\text { Contemporary cohorts } \\
\text { (2009-16) }\end{array}$} & 31528 & $\begin{array}{l}59 \\
(10)\end{array}$ & & \\
\hline
\end{tabular}

\begin{tabular}{|c|c|c|c|c|c|c|}
\hline \multirow[t]{2}{*}{ Nature of pain } & \multicolumn{2}{|c|}{$\begin{array}{l}\% \text { of patients in } \\
\text { group (range) }\end{array}$} & \multicolumn{2}{|c|}{$\begin{array}{l}\% \text { of patients with } \\
\text { obstructive CAD } \\
\text { (range) }\end{array}$} & \multicolumn{2}{|c|}{$\begin{array}{l}\text { Crude relative risk } \\
\text { of CAD (range) }\end{array}$} \\
\hline & DFRM & $\begin{array}{l}\text { Other } \\
\text { studies }\end{array}$ & DFRM & $\begin{array}{l}\text { Other } \\
\text { studies }\end{array}$ & DFRM & $\begin{array}{l}\text { Other } \\
\text { studies }\end{array}$ \\
\hline typical angina & $43 \%$ & $\begin{array}{l}14 \% \\
(7 \%-53 \%)\end{array}$ & $89 \%$ & $\begin{array}{l}27 \% \\
(9 \%-88 \%)\end{array}$ & 5.6 & $\begin{array}{l}1.7 \\
(1.1-3.0)\end{array}$ \\
\hline atypical angina & $39 \%$ & $\begin{array}{l}41 \% \\
(15 \%-87 \%)\end{array}$ & $50 \%$ & $\begin{array}{l}14 \% \\
(9 \%-72 \%)\end{array}$ & 3.1 & $\begin{array}{l}1.1 \\
(0.5-1.9)\end{array}$ \\
\hline $\begin{array}{l}\text { non-anginal chest } \\
\text { pain }\end{array}$ & $18 \%$ & $\begin{array}{l}30 \% \\
(11 \%-66 \%)\end{array}$ & $16 \%$ & $\begin{array}{l}22 \% \\
(8 \%-53 \%)\end{array}$ & 1 & 1 \\
\hline
\end{tabular}

also wide and dramatically varying crude relative rates of CAD (Table 2), such that in some studies, having atypical angina conferred a lower crude RR of CAD.

Conclusions Many of the contemporary studies assessing the DFRM constitute a lower risk cohort and we opine that classification of the nature of chest pain in several of them was very different to that used in the DFRM, such that produced striking results not consistent with other data. Although many studies have criticised the DFRM for over-estimating the rate of $\mathrm{CAD}$, we opine that some contemporary studies were intrinsically flawed, which was the opposite of what we had expected.

\section{PRIMARY CARE PRESCRIPTIONS FOR STATINS IN ENGLAND 1998-2015}

${ }^{1}$ Sadaf Raza*, ${ }^{2}$ Ketna Patel, ${ }^{3}$ Hitesh Patel, ${ }^{2}$ Christopher Primus, 'Sara Tyebally, ${ }^{2}$ Sanjeev Bhattacharyya, ${ }^{1}$ Carl Hayward. ${ }^{1}$ Bart Health NHS Trust; ${ }^{2}$ Barts Health NHS Trust; ${ }^{3}$ Imperial College London

\subsection{6/heartinl-2017-311726.91}

Introduction Statins are widely prescribed for the prevention of cardiovascular events. A change in 2014 of the National Institute for Health and Care Excellence (NICE) guidelines for the primary prevention of cardiovascular events, lowered the threshold for prescribing statins from a 10 year risk of cardiovascular events of $20 \%$ to $10 \%$. It was anticipated that this would result in over 4 million new patients commencing a statin. We sought to determine the trends in statin prescriptions in primary care in England over a 17 year period. We also analysed data from the Quality and Outcomes Framework (QOF) in 2015/16 to assess QOF achievement for prescription of statins for primary prevention.

Methods We conducted a nationwide retrospective study. Data were obtained from the Prescription Cost Analysis system, which holds information on every prescription dispensed in the community in England, covering a population of over 50 million people. We obtained data for four statins from 1998 to 2015. We analysed data collected from the Quality and Outcomes Framework, an incentive programme rewarding primary care for achieving targets. We reviewed the outcomes of care commissioning groups (CCGs) for the QOF indicator CVDPP001 defined as: for primary prevention in patients with hypertension and a cardiovascular risk assessment score $20 \%$, the proportion treated with a statin.

Results The total number of statins prescribed has increased annually from 1998 (4.5 million prescriptions) to 2015 (66.3 million prescriptions) in a sigmoid pattern (Figure 1). There has not been a significant increase in statin prescriptions since the change in NICE guidelines in 2014. The majority of statin prescriptions are for simvastatin or atorvastatin. From 1998 to 2005 both were prescribed equally and more frequently on an annual basis. In 2005 prescriptions for atorvastatin fell, then plateaued, while prescriptions for simvastatin increased. In 2012 prescriptions for atorvastatin increased while simvastatin prescriptions fell. For QOF CVDPP001, out of 209 CCGs, 49 achieved $100 \%$ and the vast majority reached $>95 \%$ (Figure 2).

Conclusions Our data demonstrate that the number of statin prescriptions has increased annually from 1998 to 2015. The 2014 NICE guidance has not resulted in a significant increase in statin prescriptions, in fact the rate of increase in prescriptions is beginning to plateau. The QOF for statin use in primary prevention has not yet adopted the new NICE guidelines and it may be that a change in prescribing trends is only seen after this occurs. The current QOF target is achieved to a high degree so it is likely that a new QOF with a $10 \%$ risk cut-off could also be met. The trends in prescribing of simvastatin and atorvastatin are likely cost driven, with an increase in simvastatin prescribing in 2004 and atorvastatin prescribing in 2012 correlating to the expiration of the UK patents for each drug. 